\title{
O esporte faz amigos, a Associação Atlética Acadêmica Rocha Lima faz o esporte
}

$\mathrm{F}$ undada em 19 de março de 1954, a Associação Atlética Acadêmica Rocha Lima (AAARL) vem, desde então, empenhando-se ao extremo para elevar o nome da "Gloriosa" Faculdade de Medicina de Ribeirão Preto da Universidade de São Paulo ao seu merecido lugar: o primeiro no pódio. Nesses 50 anos de FMRP-USP, muitas pessoas tiveram a honra de puxar o amado "Grito" da nossa faculdade, muitas tiveram a alegria de vencer o jogo de uma competição, outros, ainda, dignamente enfrentaram as inevitáveis derrotas... Graças a cada um desses momentos, a AAARL se sente, em parte, responsável, orgulhando-se de poder ver a alegria estampada no rosto de cada competidor. Esperamos continuar proporcionando tais emoções, e outras mais, a todos os alunos de nossa "Gloriosa" faculdade por outros 50 anos e mais, e mais....

\section{NOSSA HISTÓRIA}

A Associação Atlética foi fundada 2 anos após a criação da FMRP-USP, sendo, como diz seu estatuto, "independente de organizações políticas e religiosas". Apresentava, naquela época (e ainda hoje), muitas dificuldades: financeiras, falta de alunos, falta de tempo...., mas, com muito esforço, raça e "jeitinho brasileiro", todas essas adversidades foram transpostas. Teve, como seu primeiro presidente, o Doutor Akio Tanaka. Desde suas origens, a Atlética tem por objetivos "difundir a prática de desportos amadores entre seus associados, promover intercâmbio com as associações congêneres do país, colaborar com o desenvolvimento do desporto universitário e financiar, para os associados, excursões para torneios e campeonatos", tudo isso subordinado à finalidade maior: defender e elevar o nome da Faculdade de Medicina de Ribeirão Preto.
O primeiro grande avanço da Atlética foi, em 27 de agosto de 1961, a inauguração da Praça de Esportes "Zeferino Vaz", constando de ginásio poliesportivo, campo de futebol e pista de atletismo. Por algum tempo, o ginásio foi de uso exclusivo da Faculdade de Medicina, mas, a partir da década de 70, fomos obrigados a abdicar do que era, por direito, nosso. Desde então, dividimos os poucos horários de uso das quadras com as outras faculdades do Campus.

Outro projeto realizado pela AAARL foi a urbanização da praia ao redor do lago do Campus; durante muito tempo, ela serviu de local de recreação para os membros de nossa faculdade, servindo, também, como local de treino de nosso já extinta equipe de canoagem. Entretanto, devido a alguns incidentes, envolvendo banhistas, a "prainha" foi interditada, não podendo mais ser usada nem por atletas, nem por banhistas.

No decorrer de todos esses quase 50 anos de AAARL, foram vários os eventos esportivos nos quais os acadêmicos da Faculdade de Medicina de Ribeirão Preto puderam mostrar seu amor pelo esporte e pela faculdade. Como principal competição, temos a INTERMED, a maior competição universitária da América Latina. Em suas 35 edições, houve muitos momentos inesquecíveis para todos os que entraram em campo, quadra ou piscina, levando o nome de sua faculdade estampado no peito. Apesar de não costumarmos ficar em excelentes colocações, a raça demonstrada por todos os nossos atletas é digna de destaque.

A primeira INTERMED foi realizada em 1967, na cidade de Botucatu, contando com a participação de 6 faculdades de Medicina (FMRP-USP, UNESP-Botucatu, UNICAMP, Sorocaba, Santa Casa e Pinheiros). Desde então, aumentou o número de faculdades envolvidas, e hoje participam 19 faculdades, divididas em duas categorias: a PRÉ-INTERMED 
e a INTERMED propriamente dita, com 14 modalidades. Apesar da rivalidade durante os jogos, as INTERMEDs também são importantes na integracão dos acadêmicos das diversas faculdades: as festas nos alojamentos das outras faculdades mereceriam um capítulo à parte.

Infelizmente, aumentou, também, o número de brigas entre alguns enfurecidos torcedores: nas últimas edições da INTERMED, não foram poucos os exemplos de violência durante os jogos. Algumas faculdades aparentemente se esqueceram do verdadeiro intuito da competição e acabaram por desvirtuar alguns jogos. Apesar de serem punidas, as brigas ainda não parecem estar diminuindo; esperamos um dia podermos voltar aos tempos de paz, que havia nos primórdios da INTERMED.

Com ralação aos resultados, ainda não conseguimos chegar à $1^{\underline{a}}$ colocação. Podemos citar, como bons resultados, o inédito 3o lugar conseguido em 1997, na cidade de Matão, quando viemos diretamente da PRÉ-INTERMED e terminamos por alcançar nossa melhor colocação. Podemos citar também as 3 vezes nas quais alcançamos o 4ㅇl lugar: Santos - 1972, Ribeirão Preto - 1979 e novamente Ribeirão Preto 1989. Infelizmente, foram vários os episódios nos quais ficamos em péssimas posições, o que nos obrigou a disputar a PRÉ-INTERMED.

Outra competição de grande importância para todos nós é a InterUSP. É a competição que reúne as faculdades da USP mais bem organizadas na prática esportiva, apresenta elevado nível técnico em todas as modalidades, apresentando maior grau de dificuldade que a própria INTERMED. A InterUSP se iniciou aqui em Ribeirão Preto, no ano de 1972, comemorando os 20 anos da fundação de nossa faculdade. Participaram do evento, além da FMRP-USP, a ESALQ - Piracicaba, a Odontologia - Bauru e a Engenharia - São Carlos. Hoje, a InterUSP reúne oito faculdades, e acontece nos 4 dias do feriado de Corpus Cristi. Devido à quantidade de faculdades envolvidas e à pouca disponibilidade de tempo, essa competição se caracteriza por ser muito intensa, deixando atletas e torcedores exaustos ao fim dos jogos.

Além das duas mencionadas competições, participamos de muitas outras de menor importância. Podemos citar: JURP - Jogos Universitários de Ribeirão Preto - competição que reúne grande número de faculdades, e apresenta grande repercussão no meio social de Ribeirão Preto. Infelizmente, nos últimos anos, essa competição vem perdendo parte de seu brilho e sendo marcada por muitas rivalidades fora de campo, levando a algumas brigas, o que fez com que não houvesse competição em alguns anos. Podemos citar também o INTRACAMPUS, competição que reúne todos os cursos do Campus da USP - Ribeirão Preto. Nessas duas competições mostramos nossa superioridade na organização e na prática esportiva: ganhamos todos os INTRACAMPUS de que participamos e vencemos muitos JURPs, sempre disputando a liderança com a Faculdade de Educação Física da UNAERP.

Ainda existem muitas outras competições que realizamos com faculdades amigas. O BOTUBERÃO se realizou por muitos anos, alternando, ano a ano, a cidade-sede, Ribeirão Preto ou Botucatu. Por falhas na organização dos jogos, quando realizados na cidade de Botucatu, tal competição ficou esquecida por alguns anos. Mais recentemente, começou a ocorrer o PUCAMBEIRÃO, competição durante a qual a Faculdade de Medicina da PUC-Campinas vem a Ribeirão, em um final de semana, disputar todas as modalidades esportivas.

Mudando um pouco de assunto, vamos, agora, mostrar uma parte da AAARL que não está relacionada às competições. Temos, filiados à Atlética, o Núcleo de Medicina Esportiva e a Comissão Pró-Ginásio.

\section{NÚCLEO DE MEDICINA ESPORTIVA}

Há aproximadamente 5 anos, um grupo de acadêmicos da Faculdade de Medicina de Ribeirão Preto se organizou para formar um núcleo com atividades científicas, que visa aprimorar o pouco conhecimento sobre Medicina Esportiva, que nos é oferecido pela grade curricular. Assim, desde então, esse grupo estuda o papel da prática esportiva no auxílio terapêutico de muitas patologias, como hipertensão arterial, dislipidemia, osteoporose, ou, ainda, como coadjuvante na reabilitação cardiológica, pulmonar, ortopédica e neurológica. Estuda-se, também, o papel do esporte como meio preventivo, tanto em crianças, como adultos e idosos.

Tem-se, ainda, um serviço de acompanhamento de atletas, profissionais ou amadores, de modo a melhorar o desempenho deles e maximizar o uso de suas reservas físicas.

Faz parte desse núcleo uma equipe de vários profissionais, de diversas áreas, como médicos, fisioterapeuta, nutricionista e psicólogo, além de vários acadêmicos de nossa faculdade.. Esses profissionais 
agem de tal forma que, dentro de sua especialidade, tentam fazer com que o atleta use toda sua capacidade física em prol da modalidade a ser disputada.

Um dos objetivos do NUMESP é a criação de um Centro de Reabilitação, onde a Medicina Esportiva seria abordada nos 3 pilares básicos da universidade: o ensino, a pesquisa e a extensão. Para isso, contamos com o apoio da diretoria do Hospital das Clínicas da Faculdade de Medicina de Ribeirão Preto, de disciplinas de vários departamentos e da Comissão Pró-Ginásio.

A cada 2 anos, realiza-se o Encontro AAARL de Medicina Esportiva. Nesse encontro, os mais renomados especialistas do Brasil em Medicina Esportiva vêm a Ribeirão Preto debater e palestrar acerca de vários temas, todos eles relacionados aos benefícios do esporte e aos riscos de uma prática esportiva mal realizada. No encontro, tem-se, como meta, divulgar a AAARL como órgão atuante na prática da Medicina Esportiva, e divulgá-la tanto para os alunos como para a população em geral, mostrando sua importância e sua necessidade nos dias atuais.

Outras atividades são as campanhas de conscientização da população sobre os benefícios da atividade. Ocorrem seminários semanais, ministrados pe- los próprios alunos da FMRP, abertos para todos os outros acadêmicos.

\section{COMISSÃO PRÓ-GINÁSIO}

Desde a década de 70, somos forçados a dividir os horários de treinos das quadras do Campus com as outras faculdades. Os horários que nos sobram são insuficientes para nossa prática de treinos, sendo, então, necessário alugarmos quadras extras. A intenção de utilizarmos a prática esportiva como meio de reabilitação nos trouxe à mente a construção do tão sonhado ginásio da Medicina USP-Ribeirão.

A comissão Pró-Ginásio vem, ao longo de seus mais de 15 anos, juntando fundos para a realização de tão valioso projeto. Entretanto, o valor a ser atingido é muito alto, e as fontes de dinheiro são muito escassas, conta-se apenas com as doações de ex-alunos, e a realização de WorkShops de Medicina para alunos do segundo grau. Apesar de todo o trabalho, a quantidade de fundos arrecadados não está nem perto da quantidade necessária. É preciso, pois, maior apoio por parte da Diretoria da Faculdade e do Hospital das Clínicas, bem como maior auxílio por parte dos ex-alunos, para que esse projeto se realize o mais rápido possível. 